\title{
HELOs and student centred learning - where's the link?
}

Department of Education, University of Oslo, Norway

\section{Correspondence}

Rachel Sweetman, Department of Education, University of Oslo, Postboks 1092

Blindern 0317 Oslo, Norway.

Email: rachel.sweetman@iped.uio.no

\begin{abstract}
Learning outcomes are presented as a tool that can enhance teaching and learning in higher education, in particular by fostering studentcentred learning. However, the ways in which this change can and should take place and the specific kinds of enhancement involved are often unclear. This article analyses common claims about the advantages of learning outcomes for teaching and learning and their relationship to student-centred learning. The potential links between these concepts are investigated, based on interviews with teachers and students from a range of degree programmes at Norwegian and English universities. The interviews with 29 teachers and students suggest that learning outcome approaches are influencing course planning and some aspects of teaching practice, supporting more transparency and clear communication with students and offering a way to address particularly weak or traditional teaching. However, there is limited evidence that learning outcome approaches promote student-centred learning, and the analysis identifies several tensions between the challenges student-centred learning ideals pose to traditional teaching practices, in terms of transferring power and choice to students, and perceived pressures to specify and assess learning outcomes. It also suggests that teachers' and students' beliefs about the conditions and practices that lead to the most satisfying and successful elements of learning in degree courses are unlikely to be addressed through either learning-outcome or student-centred reforms.
\end{abstract}

\section{1 | THE EVOLVING PURPOSES OF HIGHER EDUCATION LEARNING OUTCOMES}

Higher education learning outcomes (HELOs) are argued to mark a fundamental paradigm shift in policy and practice from the traditional focus on teaching to a focus on student learning (Adam, 2004; Otter, 1992). HELOs are concerned with the learner's achievements rather than the teacher's intentions (Adam, 2008). This shift to student-centred learning has become central to the European higher education reform agenda, with both learning outcomes (LOs) and student-centredness gaining prominence over recent Bologna Communiqués (Sin, 2014): 'We reiterate our commitment to promote student-centred learning in higher education, characterized by innovative methods of teaching that 
involve students as active participants in their own learning' (Bucharest Bologna Communiqué, see Bologna Secretariat, 2012).

As part of the European higher education agenda, HELOs have developed from a format for expressing qualifications more clearly and consistently, to a tool that supports curricular reform, to an intervention expected to drive progress towards student-centred learning (Adam, 2008; Sin, 2014). According to Lassnigg (2012, p. 300), they can be seen as an 'attempt to implement a new governance system at the policy level which promises to change practice in a straightforward way. They are meant to be reform instruments that can change the relationships between actors, the system architecture and pedagogical practice'. However, the mechanisms whereby HELO approaches relate to student-centred learning are implicit or vague. There is little empirical research into if and how students use learning outcomes, initial studies suggesting that their weak understanding of HELOs leads to varied and limited impacts on study habits (Brooks, Dobbins, Scott, Rawlinson, \& Norman, 2014). The HELO concept and student-centredness are defined in various ways, with considerable disagreement about their nature and likely impact. By exploring how students and teachers perceive the influence of HELOs on degree course planning and practice and on learning experiences, this article sheds light on the potential relationship between HELOs and student-centred learning.

\section{I HOW MIGHT HELOs BE USED TO ENHANCE LEARNING IN DEGREE PROGRAMMES?}

The proposed benefits of HELOs include international and national qualification alignment or harmonisation, greater transparency about educational impact, enhanced quality assurance possibilities, and improved relevance of education for working life and graduate employability (Adam, 2008; ENQUA, 2010). Claims regarding their influence on teaching and learning typically relate to increased transparency; greater alignment between course aims, activities and assessment processes; and fostering student-centred environments and practices. Exactly what these enhancements mean in practice and how HELOs encourage them are often vague. Before looking at student-centred learning in greater depth, the issues of transparency and alignment learning are reviewed, as these are often presented as supportive of or overlapping with student-centredness.

HELOs are frequently argued to offer a response to broad changes in higher education, such as massification, higher expectations from students as paying customers and demands for more evidence of the impacts and benefits of higher education that demand greater transparency (Adam, 2008; ENQA, 2010). A rapid increase in student diversity also means that teaching approaches developed for small groups of able, highly-motivated students cannot meet the needs of larger, more mixed-ability cohorts (Biggs, 1999). HELOs provide a language and format that make what higher education 'does' clearer to stakeholders, particularly students, employers and policy makers (Ewell, 2007). Similarly, ongoing efforts to devise accessible, detailed and robust quality metrics for higher education often invoke HELOs as a more direct way to assess what it does (Stensaker \& Sweetman, 2014). However, how HELOs enhance learning is rendered complicated by the lack of agreement about what they are or involve. Criticised as lacking any clear theoretical basis, drawing on divergent pedagogic theories, there is disagreement about how the concept should be understood and measured (Allan, 1996; Prøitz, 2010; Smyth \& Dow, 1998). Prøitz (2010) describes how HELOs may be implemented via precise descriptions of expected outcomes, supporting more explicit instructional design and curriculum planning or with a more open sense of LOs as whatever results from education, including unintended changes. While links to specific pedagogies are vague, LOs have strong roots in 'rational curriculum design' (Allan, 1996) and are frequently associated with constructive alignment (Biggs, 1999, 2011; Kennedy, 2006). Here, curricula are designed using learning outcomes to ensure consistency across teaching activities, learning activities and assessment tasks (Kennedy, 2006). Constructive alignment is presented as an alternative to traditional teaching in higher education (Biggs, 2011) and a form of student-centred learning based on evidence about student motivation and learning (Hodge, 2010). It proposes approaches to make teaching and learning processes more explicit, with more active students adopting deeper approaches. Constructive alignment challenges the ambiguities said to characterise traditional teaching, where expectations and aims are poorly communicated. 
Critical perspectives on HELOs suggest that they can encourage over-rationalised, linear conceptions of the learning process and fail to engage with more dynamic, unpredictable and relational aspects of learning (Biesta, 2009; Hussey \& Smith, 2008; Smyth \& Dow, 1998). Ramsden (1992) cautions that the influence of learning outcomes on pedagogical practices and enhancement depends on how they are applied, as particularly strict and inflexible approaches may fragment and restrict the overall learning process. Entwistle (2009) acknowledges the risk that 'targeted understanding' approaches, such as HELOs, may encourage students to take a 'tick box' approach to learning.

\section{I HOW MIGHT HELOs RELATE TO STUDENT-CENTRED LEARNING?}

Adam (2008, p. 13) argues that student-centred learning necessitates the use of learning outcomes as the only logical approach, as it produces an automatic focus on how learners learn and the design of effective learning environments. Others argue that outcome approaches mark a shift away from traditional teacher-centred practice (Prøitz, 2010), signal moves to student-centred learning (Maher, 2004), or conflate them as the same thing (Kennedy, 2007). Such claims are hard to assess empirically. Student-centred learning is criticised for a lack of detail about what it is or how it works (Farrington, 1991; Lea, Stephenson, \& Troy, 2003; Tangney, 2014). The term is often used casually, left undefined, or conflated with ideas such as flexible learning, experiential learning, self-directed learning (O'Neil \& McMahon, 2005) and 100 more particularly active learning (Farrington, 1991). Contemporary European reforms seem to use student-centredness to 101 signal a general focus on more active learning and less traditional teaching. This lack of clarity reflects the long-standing 102 and varied roots of student- or learner-centred ideas. A key starting point for these ideas is Dewey's experiential learning. 103 'Student-centred learning' is widely attributed to Carl Rogers' perspectives on psychology, flourishing and education 104 (Brandes \& Ginnis, 1996; O'Neil \& McMahon, 2005). These perspectives challenged the traditional, authoritative role of 105 educators, the passivity of learners, and views of education as the 'transmission' of expert-defined knowledge. The term 106 student-centred has also been used to describe teachers' conceptions of learning, as a contrast to traditional teacher- and 107 content-focused understandings (Kember, 1997; 2009). The related term of 'learner-centredness', which is widely used in 108 education policy, signals an intention to move away from traditional practices, and features prominently in education 109 reforms, particularly donor-sponsored projects in developing countries (Schweisfurth, 2011). These psychological, peda- 110 gogical and policy perspectives encourage very varied ideas about what student-centred learning is for or can do.

Student-centred learning turns variously around student's choice in their education; the student doing more than the 112 lecturer (active versus passive learning); or a shift in the power relationship between the student and the teacher (O'Neil \& 113 McMahon, 2005, p. 29). It refers to 'a process in which individuals take the initiative, with or without the help of others, in 114 diagnosing their learning needs, formulating learning goals, identifying human and material resources for learning, choosing 115 and implementing learning outcomes' (Knowles, 1975 cited in Farrington, 1991, p.16). Student responsibility and activity in 116 learning are emphasised in contrast to 'teacher control and coverage of academic content in conventional, didactic teaching' 117 (Cannon \& Newble, 2000, p.16, cited in Lea et al., 2003). These definitions are not consistent in their emphasis. The former 118 stresses that students must be granted considerable agency and influence at all stages of the learning process, including 119 establishing intended outcomes; the latter stresses a shift in responsibility and agency from teachers to students and moves 120 away from traditional didactic methods. However, these competing definitions all anticipate significant shifts in practice and 121 in the role of teachers and students, expressed in metaphors for how the role of teacher is changed from 'lecturer' or 'trans- 122 mitter' to 'facilitator' or 'guide' (Wright, 2011). Exactly how far the lecturer should hand over influence remains unclear. 123

Some versions of student-centred learning seem much thinner, implying changes in teaching activity or formats, 124 whilst neglecting more substantive changes associated with the idea. Using student-centredness synonymously with 125 active learning may not only neglect but undercut more comprehensive definitions which include choice in learning 126 and shifts of power in the teacher-student relationship (O'Neil \& McMahon, 2005). Student-centredness may require 127 ongoing negotiation between the teacher and student in all key learning decisions, specifically 'What is to be learnt, 128 how and when it is to be learnt, with what outcome, what criteria and standards are to be used, how the judgements 129 are made and by whom these judgements are made' (Gibbs, 1995, p.1, cited in O'Neil \& McMahon, 2005, p. 28). Tang- 130 ney (2014) highlights how student choice and power are often overlooked in discussions of student-centred learning, 131 
suggesting that humanist ideas of holistic approaches, empowerment and emancipation are often absent in more 132 'pedagogic' discussions of the phenomena.

There is a general assumption that, despite variations in the nature and extent of shifts in roles and power 134 between teachers and students, such change is positive. Yet, an emphasis on students' perspectives and preferences 135 can de-legitimise the role of teachers, contribute to an 'absence of the academic' (Sabri, 2011) or uncritical focus on 136 student satisfaction which homogenises students and learning. It can been seen as part of what Biesta (2009) refers to 137 as 'learnification', where a focus on doing whatever is 'effective' conceals normative questions about the purposes of 138 education and who benefits from it. Moreover, the common assumption that any gain in student responsibility or 139 agency must come at the expense of teachers does not help. Student-centredness and teacher-centredness can be 140 mutually supportive, contributing to high-quality learning (Elen et al., 2007).

Finally, many authors suggest that there is more rhetoric than reality around this topic: the popularity and use of 142 the term student-centred in institutions or among teachers may not signal changes in practices (Farrington, 1991; 143 Tangney, 2014; Greener, 2015). 'Student-centred' has become a 'required criterion for academic credibility' but has 144 not 'penetrated beyond the periphery of practice' (Greener, 2015, p. 1). Teachers who claim to be doing student- 145 centred teaching have divergent views about what this involves (Farrington, 1991; Tangney, 2014).

\section{4 | IDENTIFYING KEY FEATURES OF STUDENT-CENTRED LEARNING}

These various versions of student-centredness will be used in this article to explore if, how, and in what ways HELOs 148 have an affinity or relationship with student-centred learning in general, or in selected aspects of it. The discussion above 149 suggests that most descriptions of student-centred learning invoke some or all of the key features summarised in Table I, 150 and, together, provide a way of considering forms of student-centred learning which vary in scope and intensity.

TABLE I Mapping key features of student-centred learning

\section{Key issues}

What is meant by learning? Type of learning

Nature of learning

Defining features of student-centred learning

Deep learning and understanding (Lea et al., 2003), powerful or transformational learning (Barr \& Tagg, 1995) active engagement with knowledge (Kember, 2009; Ramsden, 1992).

Knowledge not 'out there' but constructed by/within students, not 'transmitted' by teacher (Barr \& Tagg, 1995);
Practice/activities involved?

Approach to learning

$$
\text { involved? }
$$

Developing an environment supportive of learning with a focus on the learner's experience; offering variety of teaching and student activities (Kember, 2009); emphasising creativity and discovery (Ewell, 2007), active rather than passive learning (Lea et al., 2003) and developing holistic not fragmented/atomistic understanding (Barr \& Tagg, 1995).

What roles are expected? Role of the student
Students as active participants not receivers (Tangney, 2014) with increased responsibility and autonomy (Lea et al., 2003; Hodge, 2010); some role in shaping learning goals and approaches to be used; the ability to make use of variety strategies to meet varied needs (Barr \& Tagg, 1995; Wright, 2011).

Role of the teacher Designer of environment that supports learning (Barr \& Tagg, 1995) and facilitator of learning working with students as catalysts/ advisers (Wright, 2011); empower students and develop the individual student (Barr \& Tagg, 1995; Wright, 2011).

\section{Are there implications for power and choice? \\ Shifts in power}

Choice/agency
Shift away from teaching to learning encourages power to move from the teacher to the student (Barr \& Tagg, 1995); empowerment and emancipation (Tangney, 2014).

Choice of what to study and how to study it (Gibbs, 1995; Burnard, 1999 , both as cited in O'Neil \& McMahon). 
As Lea et al. (2003) note, the divergence in views about student-centred learning is not just a matter of pedagogical 152 approaches, but of underlying epistemology, and the likely implications of changes. Table I is built around four questions 153 about: the nature of knowledge or learning implied; types of activity and practices; shifts in the role of teachers and stu- 154 dents; and, the issues of power and choice in learning practices. These provide a starting point for analyses of how teach- 155 ers' and students' views and experiences reflect a varied sense of what student-centred learning is about, would look like 156 in practice, and the results it is directed at. This accepts that what counts as 'doing' student-centred learning could vary 157 considerably. Encouraging students to think about their responsibility for learning and introducing occasional 'active' tasks 158 alongside lectures could reflect a relatively thin notion. More extensive or radical versions of student-centredness could 159 involve changes where teachers cede, or at least share, control of significant aspects of the whole learning process.

\section{5 | METHODS AND DATA}

The link between HELOs and enhanced student-centred learning is analysed according to a set of interviews, from eight 162 bachelor's degree-programme cases at Norwegian and English universities (see Caspersen, Frølich and Muller in this 163 issue). The interviews (29 teaching staff and students) investigated experiences related to the use and impacts of HELOs 164 on teaching and learning. They were largely one-to-one, with a few respondents in small group interviews. The staff 165 spanned relatively new teachers and senior staff with responsibility for programme planning or additional teaching 166 responsibility (e.g. in departmental teaching and learning committees), but all were active teachers. All cases are from tra- 167 ditional, highly-ranked universities (two in each country) with similar degree programmes across the national cases. The 168 degree cases comprised four STEM programmes (two professionally oriented two pure) and four humanities pro- 169 grammes. The interviews were recorded via live notes or transcriptions from audio files. Key questions that guided the 170 interviews and analysis included: What are students' and teachers' impressions or understanding of HELO approaches?; 171 How are HELOs established/defined for the course/degree?; Are HELOs perceived as influencing changes in teaching 172 or learning or assessment practices?; What do teachers/students see as key factors determining good quality teaching/ 173 learning?; How do HELO approaches fit with their particular subject area/discipline?; What kinds of learning and knowl- 174 edge fit well/less well with HELO approaches?; Are there any challenges associated with introducing or using LOs? As 175 the analysis developed, further issues and codes emerged, notably: do LO approaches influence the role or approach of 176 teachers or students and if so, how? And, how do changes in HELOs relate to issues of power and decision making? 177

The data were gathered with comparative aims in mind. However, this analysis is not focused on disciplinary or 178 national variations (although these are mentioned where particularly relevant) but on how HELO approaches are per- 179 ceived to shape teaching and learning practices and experiences. It is also important to note certain limitations to these 180 data, which means that they may not offer a thorough cross-section of perspectives found in the two countries' higher 181 education systems overall. The universities were all research-intensive and highly-ranked, and the respondents involved 182 more senior teachers or heads of department and particularly engaged students (based on their volunteering to be inter- 183 viewed in England, or acting as class representatives in Norway). The data provide a 'snapshot' of practices and perceived 184 changes at one point in time; any claims about changes in practice linked to the introduction or use of HELOs were based 185 on the impressions of staff and students. Despite these limitations, the data provide insights from the perspective of 186 those tasked with putting HELOs into practice in degree-level teaching and those experiencing learning in these settings. 187

\section{6 | RESULTS AND ANALYSIS}

The results are presented in terms of three broad topics, aligned with the areas in Table I.

\subsection{Changes in teaching and learning practices associated with HELOs}

A key contrast that is important to note from the outset is that the term 'learning outcomes' is perceived differently in 191 Norway and England. English teachers tended to see learning outcomes as an administrative feature (a form to be filled 192 out) or re-labelling of prior terms such as 'aims and objectives'. In Norway, they were familiar as part of a wider reform 193 
process of drafting and updating course descriptions in response to new quality assurance rules. In both countries, 194 HELOs encouraged some changes in teaching that were generally welcome. The process of developing and updating 195 LOs could spark reflection, dialogue and collaboration between colleagues, potentially resulting in greater coherence 196 and teachers feeling more able to communicate what a specific degree offers their students. In several Norwegian 197 cases, the process of establishing LOs was felt to have supported more team-work in teaching.

The department went on an away day for a 'theme-building' sessions and it worked very well. A lot of people 199 have probably worked separately for a long time, and now more and more they can see that what is good for 200 the department also is good for them. That feeling has probably not been very strong before (NO4STEM 201 lecturer).

HELOs were felt to provide a way to challenge traditional teaching or support less experienced teachers. This was 204 more prominent in Norwegian cases, where teaching was, until recently, described as the private business of individual 205 lecturers. In English cases, HELOs were more likely to be described as helpful for newer or less confident teachers, pro- 206 viding a 'recipe' or guideline for planning and describing modules. They could therefore seem irrelevant to more experi- 207 enced teachers.

You might have people [teachers] who are less secure and don't know where they are going. So using it [learn- 209 ing outcomes] is a positive thing, rather than forcing it on people saying you have to do it, you can use it more 210 as a yardstick for you to use yourself.

(EN1HuLecturer)

The general feeling suggests that HELOs provide a fairly concrete, easy way to make the aims and intentions of 214 courses transparent for students and, by extension, a way of communicating the programme's content and expecta- 215 tions more explicitly. Such transparency was contrasted with some traditional approaches that lacked signposting or 216 structure to orientate students. Developing and updating LOs also provided an opportunity for some teachers to 217 review how course aims, content and activities and assessments worked together, essentially offering a renewed 218 focus on alignment. In England, it was generally expected that course LOs be reflected in assessment. In the Norwe- 219 gian cases, this was expected to emerge as a requirement, but was more likely to be in progress than in place. Both 220 countries focused more on the need to align LOs with assessments than with learning activities or processes. It was 221 unclear if clarity about LOs translated into shifts in teaching style, or changes in activities beyond final assessments. 222 Shifts in teaching approach, such as encouraging students to use different learning strategies, or engage in more int 223 learning strawere not discussed as resulting from LOs. These issues did emerge, but in more complex ways through 224 discussions about the challenge of capturing the range of knowledge and abilities involved in a degree in LO for- 225 mats. In several programmes (typically STEM/professionally-oriented courses), some felt that LOs helped to clarify 226 transferable skills (e.g. teamwork or presentations) so that they could become more prominent in assessments and 227 be built into ongoing activities in preparation for final projects or assessed tasks. Such end-of-year projects, group 228 tasks or portfolio-type assessments were seen as a good way of assessing 'ssessing sments alongside content 229 knowledge.

The content gives the technical knowledge, and we need that for our subject, but you've also got skills which 231 are technical skills. The way you assess gives you all the other skills - it could be writing it could be communi- 232 cation, it could be interpretation, that sort of thing. So the assignment gives you a lot of the more general trans- 233 ferable skills. 
Teachers and students underlined that anticipated assessment strongly determined how learning took place and how 237 students studied. Students described studying towards their assessment and teachers raised concerns that it was hard 238 to get formative activities to work, as students were often reluctant to spend time on them. Some students said they 239 referred to course LO descriptions to clarify what was expected of them, though most relied heavily on prior examples 240 of assessments or exams.

Greater clarity and transparency brought by LOs were perceived as carrying both risks and benefits. Some 242 teachers felt very specifically that LOs could be reductive or constraining, with key content and ideas simplified 243 to fit the language of outcomes. A recurring sense among teachers and students, particularly in England, was 244 that, whilst clarity was valuable, it was only possible and desirable to explain some of what was to be learned. At 245 some point, students must make sense of things for themselves. There was a sense that efforts to specify how 246 students were expected to perform could go too far, to become 'spoon feeding' or encourage a 'tick box' 247 approach to the course.

We can do all that work (preparing them) and they can still write a bad essay, because they can't synthesise all 249 the material and put it all together. That still has to be their process. It isn't something you can teach in an hour 250 or tell someone how to do. (EN1HuLecturer)

Many teachers felt that, while LOs could help to communicate some aspects of degree-level learning, students still had 253 to engage with a learning process which was personal and contained areas of uncertainty and confusion, where they 254 were not clear about what they were learning until they had learnt it. Students also acknowledged that, whilst clear 255 information about courses content, organisation, and what they should be able to do was useful, there were limits to 256 what it could convey.

People always ask if they can get hold of earlier exams and see how they look. . I think a lot of people found 258 that we didn't know how you should read the course literature. Should we take notes while we read? It took 259 quite a long time to work that sort of thing out. (NO4HuStudent)

There were also questions about the extent to which LOs could capture differing levels of performance. LOs were gen- 262 erally seen as specifying a minimum or general level of achievement, but were felt to be a poor way to communicate 263 what it would mean to excel, as that often involved going beyond basic criteria and doing something creative or unex- 264 pected. Similarly, tensions were expressed about using LOs in courses where the aim was to encourage students to 265 realise that there were many ways to address an issue or solve a problem. These concerns about the limitations of LOs 266 were less prominent in Norway and in more vocationally-oriented programmes. One possible reason could be that the 267 boundaries of 'core outcomes' were harder to define in these subjects.

When the first drafts of learning outcomes were circulated the [natural sciences and maths courses] had three 269 points. Languages had a long list. While the first is clear end targeted - those programmes culminate in a spe- 270 cific [employment] area... It's not so obvious what you should have in a more general subject like a language. 271 (NO1HuLeader)

Limitations of LOs, and the way they might fail to capture aspects of learning, suggest an ambiguous relationship 274 between LOs, transparency, and the learning experienced in degrees. The range of responses suggests that LOs can be 275 an effective way to map key landmarks, or more granular points to be learned from a course, but both the individual 276 process of learning, and certain important types of learning, are difficult to express in an outcomes format. Implement- 277 ing learning outcomes in the name of transparency therefore carries risks of stripping away meaning, or of encouraging 278 students to perform in a more instrumental way. 
I think a lot of academics [ ] feel that this is an illusory clarity; it's sort of, trying to pretend that the terrain of 280 learning and teaching is simpler and easier to explain than it actually is. The result of that are these sorts of 281 frustrations: students want more and more clarity and academics are saying, 'well, you know, more clarity than 282 this isn't possible. I have already written five pages of explanation about how to do your assessment. That is 283 enough. It's not possible to specify in greater detail than that'. . you reach a point where students are not mak- 284 ing judgments that they need to make. (EN2HuLecturer)

\subsection{Changes in student and teacher roles associated with HELOs}

Neither students' nor teachers' comments revealed a sense of their roles shifting considerably with a LO approach. 288 Teachers did not seem to feel that LOs helped them to transfer responsibility for learning to their students. Although 289 they expressed interest in encouraging students to work independently and be active, teachers largely relied on the 290 pressure of assessments, and occasionally on mandatory tasks or group work to 'make' students work outside lectures. 291 Teachers felt pressure to increase student satisfaction (expressed via surveys) and were concerned with improving the 292 quality of courses and teaching. These aspirations were felt to be frustrated not by their preference for 'traditional' 293 teaching, but by a context typified by increasing class sizes, more varied student bodies with mixed abilities, and a 294 diversity of students' interests and future plans.

The way we teach has gone through enormous changes with increases in our cohort sizes, and I think we're 296 currently going through a period of self-reflection, and whilst we focus an awful lot on the student experience, 297 I think there's actually also been a disconnect and a reduction in staff morale from their perspective. Because if 298 the class sizes start getting large, how do the staff connect with the student is challenging. Communication is 299 two way, engagement is two way. (EN2STEMLecturer) 300

The enhanced clarity that LOs could offer was felt to help students to orient themselves, and to some extent offered 302 them a clearer sense of what was expected of them. However, teachers' comments about the process of using LOs 303 seemed to suggest this increased clarity did not lead to students taking on more responsibility and agency. Teachers 304 still felt that they would be seen as responsible for the success or failure of students on a course, often believing stu- 305 dents needed to be coerced or forced to engage with learning, rather than simply given the opportunity and resources. 306 This reflects a traditional sense of the teachers' role in defining and channelling learning activity. Students and teachers 307 recognised that, whilst programmes gave opportunities for learning, it was ultimately down to the students how hard 308 they worked and how they did.

Students are surprisingly conservative - sitting there doing nothing at all, they only listen, they are passive 310 recipients of information. [ ] Students would learn more if they did more. (NO4STEMLecturer) 311

Some teachers and students raised concerns, particularly in England, that LOs encouraged a consumer orientation. The 313 idea that students can expect to 'receive' certain outcomes from a course, which can be specified in advance, could be 314 perceived as a form of quasi-contract, encouraging a passive role.

Students described their role as learners changing during their courses, and experiencing some learning as more 316 active and deep. However, this was not related to LOs or practices associated with them, but to engagement with spe- 317 cific bodies of knowledge that interested them, where they talked about feeling they were learning in a different way, 318 moving into a different role or changing in themselves. Students referred to excellent lectures or relationships with 319 specific teachers providing feedback on traditional assessment tasks.

Teachers and students valued elements of more traditional, teacher-centred education, notably high-quality lec- 321 tures and essay assignments including detailed, personal feedback. Approaches seen as more student-centred, such as 322 smaller group seminars, summative tasks and opportunities for ongoing feedback and guidance were also mentioned 323 
as good ways to engage students and develop a more collaborative relationship between teachers and students. These 324 were often felt to be limited by resource constraints, not teacher attitudes or a lack of LO approaches supporting 325 them. Teachers wanting to make use of more varied and active approaches in teaching repeatedly suggested that this 326 was constrained by resources (class sizes and formats, teacher time for preparation and contact). They also suggested 327 that students' unwillingness to engage with tasks that did not count towards a final grade made more activities or sum- 328 mative tasks a challenge.

When I talk to small groups you can see lights coming on 'oh, that's why we're doing that'. I said earlier that I 330 think marks are a barrier to learning, and I still think they are, but in some cases because students will focus on 331 what mark they will get rather than what they are learning and the skills they were developing. (EN1STEMLec- 332 turer/leader)

\section{3 | HELOS and issues of power and choice}

The design of degree programmes and balancing compulsory and optional modules were related to teachers' roles and 336 issues of power and choice. Although having some choice about courses was important to students, it seemed that nei- 337 ther they nor teachers felt that students should have more power in determining the overall shape and content of 338 degrees. Students and teachers suggested that a key part of the teacher's role was to understand the 'big picture' of a 339 discipline or professional area and guide students into it. Teachers underlined this selection and prioritisation of con- 340 tent and knowledge as central to their role.

Students wanted the security of knowing that their degree included 'core' knowledge for their field, but were also 342 enthusiastic about tailoring their degree to their interests and abilities. Teachers thought that degrees (particularly in 343 the humanities) provided many opportunities to follow various 'tracks' within programmes, based on student preferen- 344 ces. Whilst popular, this was noted as in tension with aspirations for LOs to support coherence and standardisation: 345 modular degrees and varied discipline sub-fields made identifying 'core' or common LOs at the degree level more diffi- 346 cult. Students were also aware that their selection of courses and the range of skills or knowledge they were develop- 347 ing could vary a great deal. They did not expect to end up with the same LOs as their peers in many cases, and were 348 aware of pursuing diverse ambitions. This was more common in humanities/languages.

You end up doing something completely different than the person sat next to you. Especially in things like the 350 essay - people are doing things on all kinds of different examples and materials. (EN2HuStudent) 351

Explicit discussions of power were not a feature in the interviews. To the extent that any sense of power struggles 353 emerged, it related to the issues of students as consumers, a 'student rights' orientation to learning, or challenging 354 results from assessments. There was concern that by defining what students could 'expect', or should 'receive', from a 355 degree, they may see themselves more as consumers, or blame the teacher or institution if they were unsatisfied with 356 their degree results. Some felt power was shifting away from teachers and students towards managers or heads of 357 departments. Changes related to LOs that were generally received positively, such as making the teachers' and depart- 358 ment's aims more explicit, did inevitably seem to reduce the scope for student steering of the educational journey.

\section{CONCLUDING COMMENTS AND IMPLICATIONS}

The analysis suggests that learning outcomes are influencing aspects of course planning and teaching practice, but the 361 extent and nature of this influence varies, and the implications of these changes are neither seen as entirely positive or 362 clearly supportive of most features of student-centred learning. The assumption that more learning outcome-based or 363 student-centred approaches are priorities for teachers and students is also questioned. 
10

There are signs that LOs encourage a focus on transparency and alignment, safeguarding against weaker teaching 365 practices or challenge cases of particularly traditional teaching. Elements of constructive alignment were suggested in 366 the interviews in aspirations to link LOs and assessment more explicitly; however there were no signs of significant 367 influence on overall alignment across intended outcomes, teaching approaches or activities, and assessment. There 368 was also little sign of LOs shaping or shifting teachers' approaches or day-to-day activities, or encouraging more activ- 369 ity and responsibility among students. The exception here is the few cases that integrate subject-specific and generic 370 LOs through final assessments involving project or group tasks. There is some scope to suggest that by re-working 371 courses in the language of outcomes, teachers have new opportunities to reflect on how they communicate content 372 and expectations to students more clearly and collaborate to develop students' learning over a whole degree. Overall, 373 however, the results offer little support for claims that HELOs are sparking a paradigm shift in teaching and learning, or 374 Adam's (2008) argument that learning outcomes necessarily support more learner-focused and effective environments. 375

One possible explanation for this limited influence is the lack of theoretical and practical clarity around both 376 HELOs and student-centred learning; this may mean neither is put into practice with the consistency required for 377 teachers or students to recognise a shift. Individual courses and actors may put them to work in ad-hoc ways which 378 undermine any systematic changes. Previous studies have suggested that students only experienced student-centred 379 learning reforms as a significant change when there was a substantial, collective shift in practices and acceptance of 380 common philosophies about learning and the aims of education (Kember, 2009; Elen et al., 2007).

It is also significant that several of the key features related to more substantive or wide-ranging notions of 382 student-centred learning, such as engagement with knowledge, shifts in roles and power and student input about what 383 is learnt, how, and how success is determined are not prominent. Whilst teachers express an interest in helping their 384 students to engage with their subject and be more active and independent, it does not seem that LO approaches are 385 helping them achieve this. Whilst clarity about what is expected of students is generally seen as helpful, the results 386 also show concerns from students and teachers about the potential of too much specification and pre-definition of 387 learning in higher education, with potential constraints on flexibility and variety, or fostering more instrumental learn- 388 ing. Hence, an LO approach could even undermine features of student-centred learning where they stress students' 389 individuality and agency in developing knowledge.

Whilst an opposition between teacher- and student-centred approaches is often implied, the results suggest that 391 neither extreme may be particularly achievable or desirable in practice. Most cases reflect a balance being sought 392 between more traditional 'delivery' of teaching through lectures, and varied assessment approaches which draw upon 393 broader skills and content knowledge. The experiences teachers and students raised as particularly successful or 394 engaging include aspects of teacher- and student-centred features. Here, and in previous studies (Elen, Clarebout, 395 Léonard, \& Lowyck, 2007), students express a preference for a combination of both forms: clear guidance, feedback 396 and the expertise of a teacher telling them what to learn and how, with room left for personalisation and creativity. 397 Ellen et al. (2007) refer to this as a 'safe and challenging learning environment', suggesting teacher- and student- 398 centred approaches should not be presented or applied as independent and competing, but related and complementary 399 features of high-quality higher education.

HELOs' role in enhanced transparency and some minimal alignment of programmes may be important in guarding 401 against poor quality courses, but enhancing learning, or supporting the most satisfying and transformational aspects of 402 learning seem to involve issues which neither HELOs, nor 'thinner' versions of student-centred learning connect with in 403 practice: engagement with specific bodies of knowledge, relationships between students and teachers, and individual 404 transformation. The clarity offered by LOs as an unadulterated positive, may have more mixed implications for how learn- 405 ing is understood and approached by teachers and students. Expectations that all aspects of degree programmes should 406 be made as explicit as possible simply do not fit with high-level learning: individual judgement, variety and creativity and 407 independent knowledge development may be undermined. Aspects of learning that are harder to express and assess may 408 be neglected. Features of student-centred learning transferring choice and power about what is to be learned and how 409 seem to be an uncomfortable fit where LOs lead to increasingly fixed and specified course plans and success criteria. 
It seems possible that a focus on HELOs and student-centred learning in reform agendas may divert attention 411 from more basic issues that teachers and students perceive as more important to quality learning. One reason sug- 412 gested for student-centred approaches to tend to be less evident in practice than in rhetoric and intentions is that 413 student-centred learning, in most incarnations, is likely to require more resources and demand more input and planning 414 from teachers than traditional methods (Lea, Stephenson, \& Troy, 2003). The challenges of larger classes and limited 415 teaching resources may make significant changes in teaching and learning activities, increases in contact time, or the 416 development of more supportive, challenging learning environments, hard to achieve.

The implications are that it seems unlikely that HELOs will trigger profound shifts or enhancements in teaching 418 quality and learning in isolation. The challenge of meeting teachers' and students' interest in more satisfying and pro- 419 found learning experiences, or developing more substantive student-centred learning, seem to be limited by students 420 and teachers wanting a balance between teacher- and student-centred practices and by environments of growing class 421 sizes and resource constraints.

Finally, if HELOs continue to be used more explicitly in planning and aligning courses, it is important to consider 423 the potential for them to have detrimental as well as positive impacts on the learning process. This reflects concerns 424 raised in the literature (Entwistle, 2009; Hussey \& Smith, 2008; Biesta, 2009) that outcomes need to leave space for 425 elements of uncertainty and varied, personal outcomes if they are to support the development of enhanced teaching 426 and learning in higher education.

\section{REFERENCES}

Adam, S. (2004). Using Learning Outcomes: A consideration of the nature, role, application and implications for European edu- 429 cation of employing "learning outcomes" at the local, national and international levels. Presented at the United Kingdom 430 Bologna Seminar, Heriot-Watt University, Edinburgh, Scotland.

Adam, S. (2008). Learning outcomes current developments in Europe: update on the issues and applications of learning out- 432 comes associated with the bologna process. Prepared for the Bologna Seminar: Learning outcomes based higher educa- 433 tion: The Scottish experience, 21- 22 February 2008, at Heriot-Watt University, Edinburgh, Scotland. 434

Allan, J. (1996). Learning outcomes in higher education, Studies in Higher Education, 21, 93-108. 435

Barr, R. B., \& Tagg, J. (1995). From teaching to learning-A new paradigm for undergraduate education, Change: The mag- 436 azine of higher learning, 27, 12-26.

Biesta, G. (2009). Good education in an age of measurement: On the need to reconnect with the question of purpose in 438 education, Educational Assessment, Evaluation and Accountability (Formerly: Journal of Personnel Evaluation in Educa- 439 tion), 21, 33-46.

Biggs, J. (1999). What the student does: Teaching for enhanced learning, Higher Education Research \& Development, 18,441 57-75.

Biggs, J. B. (2011). Teaching for Quality Learning at University: What the student does (McGraw-Hill Education, UK).

Bologna Secretariat (2012). Making the Most of our Potential: Consolidating the European Higher Education Area. Bucharest 444 Communiqué. In 2012 EHEA Ministerial Conference and 3rd Bologna Policy Forum Documents. 445

Brandes, D., \& Ginnis, P. (1996). A Guide to Student-centred Learning (Nelson Thornes). 446

Brooks, S., Dobbins, K., Scott, J. J. A., Rawlinson, M., \& Norman, R. I. (2014). Learning about learning outcomes: The stu- 447 dent perspective, Teaching in Higher Education, 19, 721-733.

Elen, J., Clarebout, G., Léonard, R., \& Lowyck, J. (2007). Student-centred and teacher-centred learning environments: 449 What students think, Teaching in Higher Education, 12, 105-117.

Enqa (2010). Quality Assurance and Learning Outcomes. Workshop Report 17 (Helsinki, European Association for Quality 451 Assurance in Higher Education).

Entwistle, N. J. (2009) Teaching for Understanding at University (Palgrave Macmillan).

Ewell, P. (2007). Applying learning outcomes concepts to higher education: An overview. Prepared for the Hong Kong 454 University Grants Committee.

Farrington, I. (1991). Student-centred learning: Rhetoric and reality? Journal of Further and Higher Education, 15, 16-21. 456

Greener, S. (2015). What do we mean by "student-centred" learning? Interactive Learning Environments, 23, 1-2. 457

Hodge, S. (2010). Student-centred Learning in Higher Education and Adult Education. Occasional Papers on Learning and 458 Teaching at University of South Africa (UniSA). Paper 3. http://scholar.googleusercontent.com/scholar? 459 $\mathrm{q}=$ cache:6aCAaPADXs4J:scholar.google.com/\&hl=en\&as_sdt $=2005 \&$ sciodt $=0,5$ 
Hussey, T., \& Smith, P. (2008). Learning outcomes: Aconceptual analysis, Teaching in Higher Education, 13, $107-115$.

Kember, D. (1997). A reconceptualisation of the research into university academics' conceptions of teaching, Learning and 462 Instruction, 7, 255-275.

Kember, D. (2009). Promoting student-centred forms of learning across an entire university, Higher Education, 58, 1-13. 464

Kennedy, D. (2006). Writing and Using Learning Outcomes: A practical guide (University College Cork). 465

Lassnigg, L. (2012). 'Lost in translation': Learning outcomes and the governance of education, Journal of education and 466 work, 25, 299-330.

Lea, S. J., Stephenson, D., \& Troy, J. (2003). Higher education students' attitudes to student-centred learning: Beyond 468 "educational bulimia"? Studies in Higher Education, 28, 321-334. 469

Maher, A. (2004). Learning outcomes in higher education: Implications for curriculum design and student learning, Journal 470 of Hospitality, Leisure, Sport and Tourism Education, 3, 46-54. 471

O'neill, G., \& Mcmahon, T. (2005). Student-centred learning: what does it mean for students and lecturers. In: editors? 472 Emerging issues in the practice of university learning and teaching (Dublin, AISHE). http://sclthailand.org/2011/08/stu- 473 dent-centered-learning-what-does-it-mean-for-students-and-lecturers/ 474

Otter, S. (1992). Learning Outcomes in Higher Education. A Development Project Report (273) (London, UDACE, Further 475 Education Unit. Department of Employment). http://files.eric.ed.gov/fulltext/ED354397.pdf 476

Prøitz, T. S. (2010). Learning outcomes: What are they? Who defines them? When and where are they defined? Educa- 477 tional Assessment, Evaluation and Accountability, 22, 119-137. 478

Ramsden, P. (1992). Learning to Teach in Higher Education (London, Routledge). 479

Sabri, D. (2011). What's wrong with "the student experience"? Discourse: Studies in the Cultural Politics of Education, 32,480 657-667.

Schweisfurth, M. (2011). Learner-centred education in developing country contexts: from solution to problem? Interna- 482 tional Journal of Educational Development, 31, 425-432. 483

Sin, C. (2014). Teaching and learning: a journey from the margins to the core in European higher education policy, In: A. 484 Curaj, L. Matei, R. Pricopie, J. Salmi, \& P. Scott (Eds.), The European Higher Education Area: Between critical reflections 485 and future policies (Dordrecht, Springer, 325-341).

Smyth, J., \& Dow, A. (1998). What's wrong with outcomes? Spotter planes, action plans, and steerage of the educational 487 workplace, British Journal of Sociology of Education, 19, 291-303. 488

Stensaker, B., \& Sweetman, R. (2014). Impact of assessment initiatives on quality assurance, In: H. Coates (Ed) Higher Edu- 489 cation Learning Outcomes Assessment (Peter Lang Publishing Group, Part 3, Chapter 3. s 237 -259.). 490

Tangney, S. (2014). Student-centred learning: A humanist perspective, Teaching in Higher Education, 19, $266-275$.

Wright, G. B. (2011). Student-centered learning in higher education, International Journal of Teaching and Learning in 492 Higher Education, 23, 92-97.

How to cite this article: Sweetman R. HELOs and student centred learning - where's the link?. Eur J Educ. 2016;00:1-12. doi:10.1111/ejed.12202. 


\section{AUTHOR QUERY FORM}

Dear Author,

During the preparation of your manuscript for publication, the questions listed below have arisen. Please attend to these matters and return this form with your proof.

Many thanks for your assistance.

\begin{tabular}{|l|l|l|}
\hline $\begin{array}{l}\text { Query } \\
\text { References }\end{array}$ & Query & Remarks \\
\hline AQ1 & Query author missing editors name & \\
\hline AQ2 & $\begin{array}{l}\text { Please confirm that given names (red) and surnames/family names (green) have } \\
\text { been identified correctly. }\end{array}$ & \\
\hline
\end{tabular}

